\title{
Big Data Accumulation of L-Shape Extruded Alloys for Interior Parts for High-Speed Trains
}

\author{
Kee Joo Kim, Tae-Kook Kim
}

\begin{abstract}
L-Shape extruded alloys were manufactured by adopting aluminum alloy as the candidate lightweight alloy to be used for interior and exterior materials of high-speed trains. The cast product was extruded using the air slip (AS) casting method and the direct casting (DC) method. The product was again heat-treated with T5 or T6 tempering. According to literature research, the candidate alloys were selected as 6063, 6N01, 6061, 6060, 6005 and 5083 alloys. These alloys were extruded after casting and heat-treated and their properties such as the hardness, microstructure and tensile properties were evaluated. The hardness, microstructure and tensile properties of the selected 6063, 6N01, 6061, 6005 and 5083 aluminum alloys in the present study are similar to those of external materials made by Alcan, Canada. Mechanical properties of the extruded materials were comparable to those of external materials (manufactured by Canada, Alcan). The hardness, microstructure, and extrusion characteristics of AA6063, AA6N01, AA6061, AA6005, AA6060 and $A A 5083$ alloys selected in the present study through literature review are similar to those of external materials (Canada, Alcan). By performing extrusion, under the conditions of high-speed railway, the process conditions for manufacturing extruded materials with complicated shape to meet the requirements of vibration resistance and airtightness have been established. Therefore, it was proved to be sufficient as the interior and exterior materials of high-speed train.
\end{abstract}

Keywords : Extrusion, Interior Parts, High-Speed Trains, Casting, Aluminum Alloys, Tensile

\section{INTRODUCTION}

G enerally, it is essential to improve the performance of propulsion engines, lighten the structure and improve the output and speed of transportation equipment such as automobiles and railroads. The materials used for high-speed trains should be implemented together with the improvement in physical properties to withstand harsh operating conditions associated with high-speed operation. High-speed trains requires a higher level of physical characteristics than those of conventional railway vehicles due to the increase of the impact amount from high-speed operation, the increase of vibration, the increase of frictional force and heat generation. Additionally, it is necessary to pay close attention to sound insulation, vibration, and so on for comfortable operation suitable for high-speed and expensive transportation[1]. As the development of high-speed trains progresses, the amount of steel and stainless steel used in strain vehicle decreases.

Revised Manuscript Received on July 22, 2019.

Kee Joo Kim, Dept. of Mechatronics Engineering, Tongmyong University, Busan, Republic of Korea. Email: kjkim@tu.ac.kr

Tae-Kook Kim*, Dept. of Information and Communications Engineering, Tongmyong University, Busan, Republic of Korea. Email: leader@tu.ac.kr
However, the amount of aluminum alloy used increases, gradually increasing the level of light weight[1-4].

Due to the aforementioned requirements for high-speed operation, there is a need for a high level of geometric accuracy compared with conventional railway vehicles for comfortable operation suitable for high-speed and expensive transportation. Besides mechanical strength, it is important to consider extrusion properties for materials in interior and exterior parts of high-speed trains. Direct casting (DC) and air slip (AS) casting are available for casting. In AS casting method, the effective mold height at which cooling water is injected from the mold contact point is lower than that of DC casting method[5-8]. Therefore, the ingot surface is relatively smooth, and the thickness of abnormal layer such as inverse-segregated layer is also thinned. Additionally, because molten metal is smoothly and evenly distributed in the mold during casting, oxides, non-metallic inclusions and hydrogen gas-free billets can be produced. In the case of AS casting, it is possible to eliminate the problems such as loss of casting operation, low recovery rate, poor surface condition of billet. These problems can be found in DC casting method due to float adjustment immature and blocked spout. Therefore, the recovery rate in casting can be increased in AS casting.

In the present study, we selected the alloys used in existing high-speed trains through literature surveys. These alloy castings were extruded and their physical properties were evaluated.

\section{EXPERIMENTAL METHODS}

In the present study, the candidate alloys were selected as 6063, 6N01, 6061, 6060, 6005 and 5083 alloys through literature surveys. These alloys were extruded after casting and their properties were evaluated. In the present study, DC casting method and AS casting method were used to compare the characteristics of extruded shapes according to casting characteristics. By performing extrusion, under the conditions of high-speed railway, the process conditions for manufacturing extruded materials with complicated shape to meet the requirements of vibration resistance and airtightness have been established[1]. The cast materials were extruded and subjected to $\mathrm{T} 5$ or $\mathrm{T} 6$ heat treatment. These microstructures were also observed to analyze the mechanical properties. Fig. 1 shows the test section of the material after extrusion, and the dimensions of this shape were analyzed. The tolerance was adjusted to the first decimal point and the dimensional accuracy was confirmed. 
The hardness and tensile tests of the extruded alloy were carried out to evaluate mechanical properties and to compare the extruded 6063 alloy fabricated in this study with the 6063 alloy imported from A-Co. in Canada. The differences using AS casting method and DC casting method were compared as well. The hardness test was carried out using a Vickers hardness tester with a load of $50 \mathrm{~N}$ and holding time of $15 \mathrm{~s}$. For tensile test, the sheet type tensile specimens were fabricated and the specimen size was determined following ASTM E8, as shown in Fig. 2. The fine load change was measured using an Instron material tester of $5 \mathrm{kN}$ capacity. The initial tensile speed was $5 \times 10^{-4} / \mathrm{sec}$. The specimen grip was a wedge-shaped plate one and the elongation was measured using an extensometer[1,9,10].

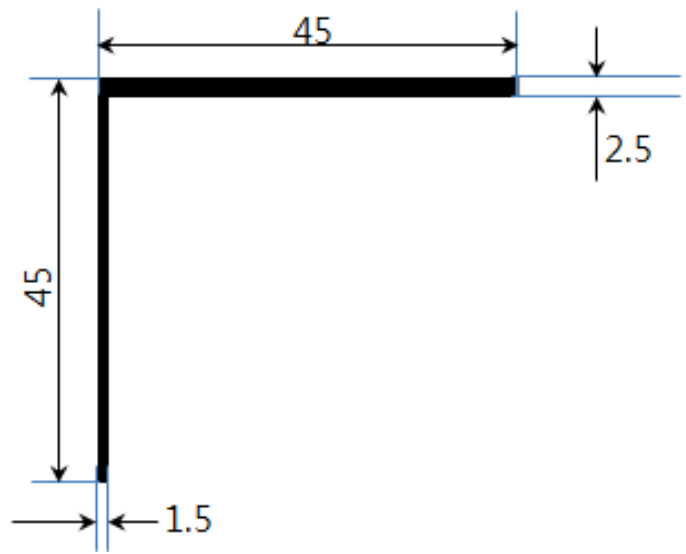

Figure 1: Geometry and dimension of extrusion test profile. Unit [mm]

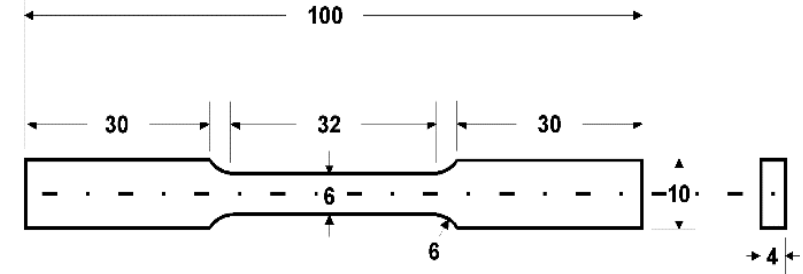

Figure 2: Geometry of tensile test specimen

\section{EXPERIMENTAL RESULTS AND DISCUSSION}

Table 1 shows the extrusion conditions according to the extruded materials evaluated in this study. It is worth noting that the extrusion temperature and extrusion pressure of 6061 alloy were somewhat higher than those of other alloys.

Table 1: Extrusion test conditions

\begin{tabular}{|c|c|c|c|c|}
\hline Alloys & $\begin{array}{c}\text { Billet } \\
\text { Temp. }\left({ }^{\circ} \mathbf{C}\right)\end{array}$ & $\begin{array}{c}\text { Press } \\
\text { ure } \\
(\mathbf{k g} / \mathbf{c m} \\
\mathbf{2})\end{array}$ & $\begin{array}{c}\text { Ram } \\
\text { Speed } \\
(\mathbf{m m} / \mathbf{s} \\
\mathbf{e c})\end{array}$ & $\begin{array}{c}\text { Produc } \\
\text { t Speed } \\
(\mathbf{m} / \mathbf{m i n})\end{array}$ \\
\hline 6063 & 450 & 175 & 7.7 & 40 \\
\hline 6061 & 470 & 195 & 5.8 & 30 \\
\hline $6 \mathrm{N01}$ & 460 & 185 & 6.7 & 35 \\
\hline $6063+\alpha$ & 450 & 175 & 7.1 & 37 \\
\hline 6005 & 610 & 150 & 5.0 & 28 \\
\hline 6060 & 600 & 130 & 6.0 & 36 \\
\hline 5083 & 300 & 200 & 1.0 & 4 \\
\hline
\end{tabular}

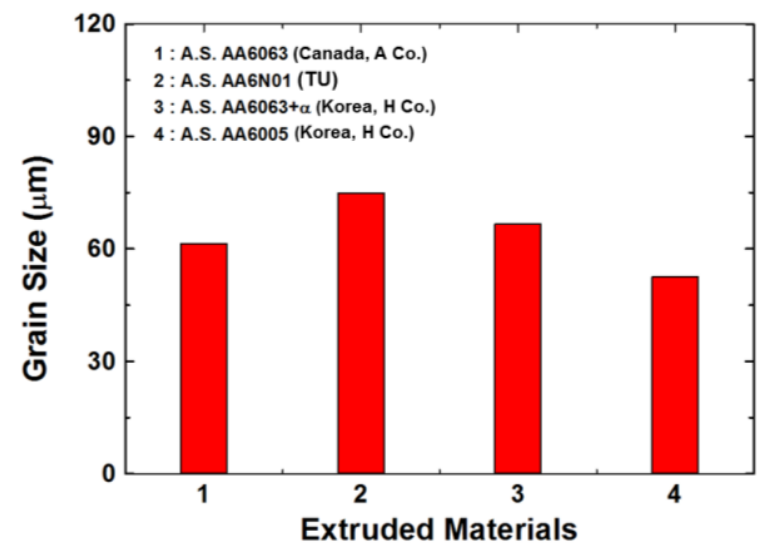

Figure 3: Grain size of extruded materials

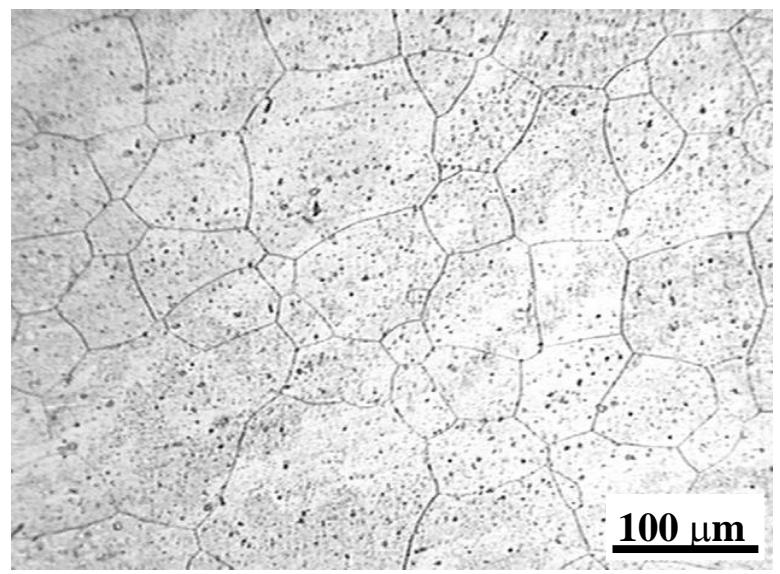

Figure 4: Microstructure of 6N01 after AS casting and extrusion (TU)[9]

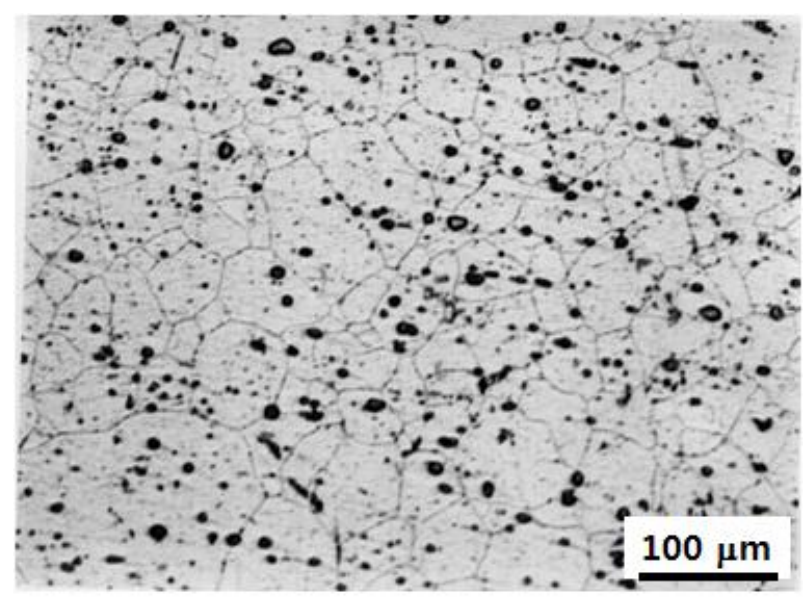

Figure 5: Microstructure of 6005 after AS casting and extrusion (Korea H Co.)

Microstructure observation was carried out to analyze the mechanical properties of the extruded material. Fig. 3 shows the measurement results of the grain size of the extruded materials. Fig. 4 and Fig. 5 show the microstructure photographs of the AS extruded material 6N01 (manufactured by TU) and the AS extruded material 6063 + a (manufactured by Korea H Company). Among the extruded materials, the grain size of the 6005 aluminum alloy manufactured by Korea $\mathrm{H}$ Co., Ltd. was also the finest. 


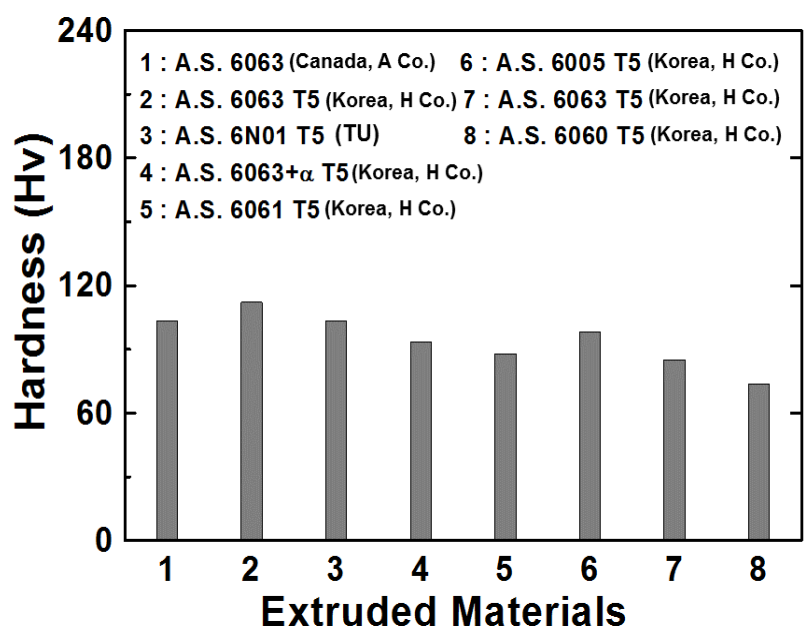

Figure 6: Results of Vickers hardness test

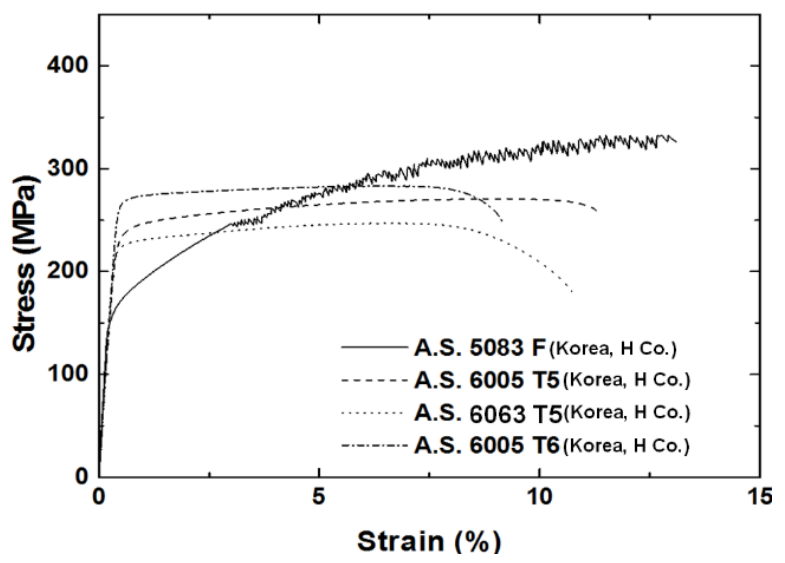

Figure 7: Stress-strain curves of AA5083F, 6005 T5, 6063 T5 and 6005 T6 during tensile test

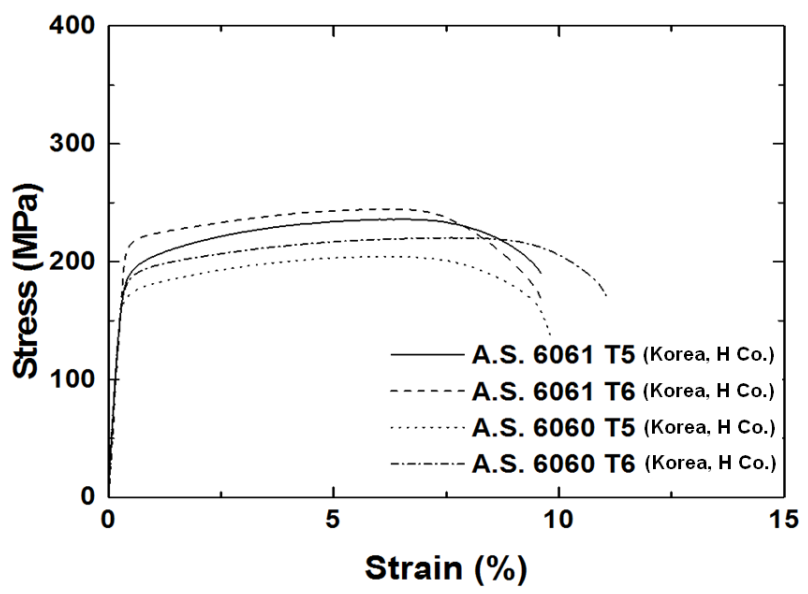

Figure 8: Stress-strain curves of AA6061 T5, T6 and 6060 T5, T6 during tensile test

Fig. 6 shows the hardness test results. The 6063 T5 (manufactured by Korea H Co., Ltd.) alloy extruded from the AS cast product exhibited the highest hardness values.

Fig. 7 and Fig. 8 show the results of tensile test after T5 or T6 heat treatment of the materials extruded from the cast materials. The 6005 extruded material exhibited relatively high tensile properties and ductility, and the work hardening index showed similar values.

To identify these data more quantitatively, Fig. 9 shows the tensile test results of the extruded materials. It was found that the $6 \mathrm{xxx}$ series alloy produced in this study showed mechanical characteristics similar to those of the alloy manufactured by A-Co. in Canada. Thus, the mechanical properties of the extruded alloys can be successfully localized.

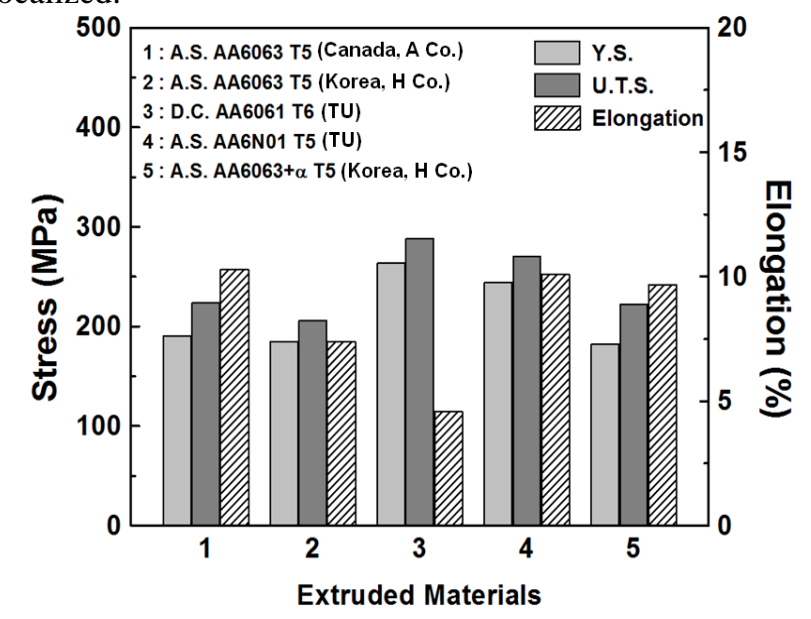

(a) AA6063, 6061, 6N01, 6063+ $\alpha$

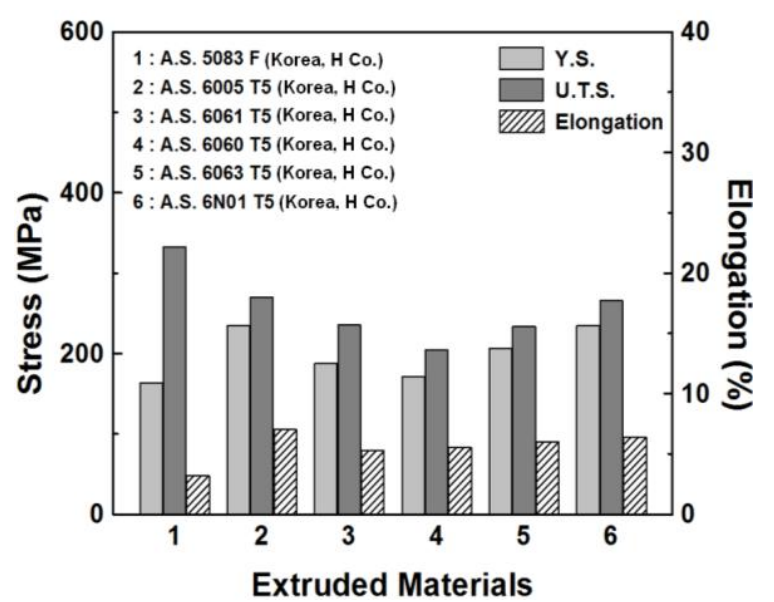

(b) AA5083, 6005, 6061, 6060, 6063, 6N01

Figure 9: Mechanical properties of 6xxx extruded materials after tensile test

The fracture surfaces of the extruded materials after tensile test were observed using a scanning electron microscope (SEM).

Fig. 10-Fig. 16 show SEM images of the extruded materials after tensile tests. Consequently, most specimens presented typical dimple ductile fractures. Especially, as Fig. 11 shows, after DC casting, the extruded 6061 material (manufactured by TU) had a brittle fracture appearance, which occurred due to grain boundary segregation of impurities. There was almost no difference between the DC casting and AS casting method when the microstructure was observed. 


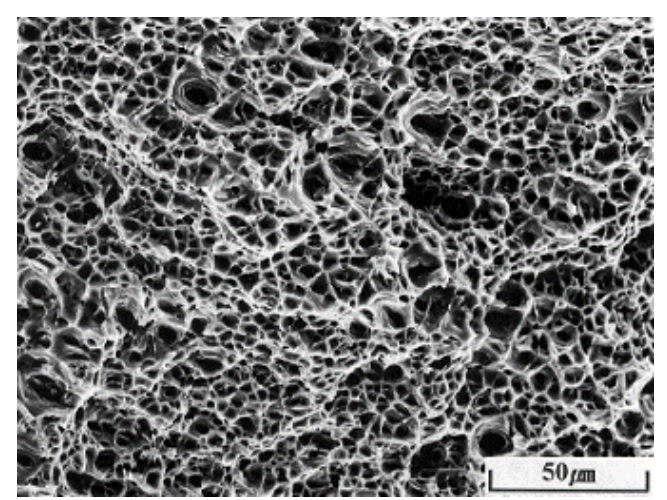

(a) Low magnification

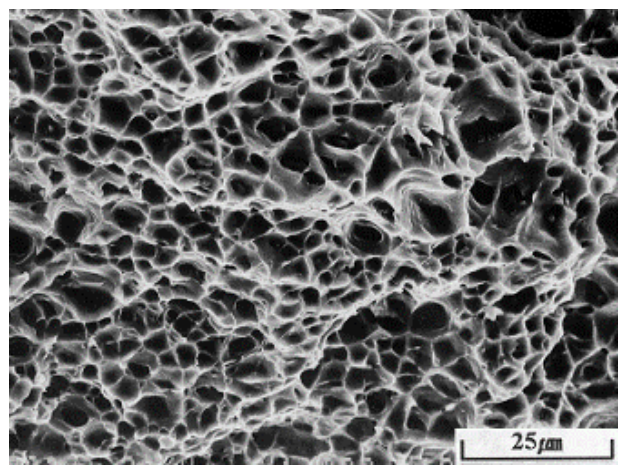

(b) High magnification

Figure 10: SEM fractography of 6063 after AS casting and extrusion (Korea H Co.)[ 9]

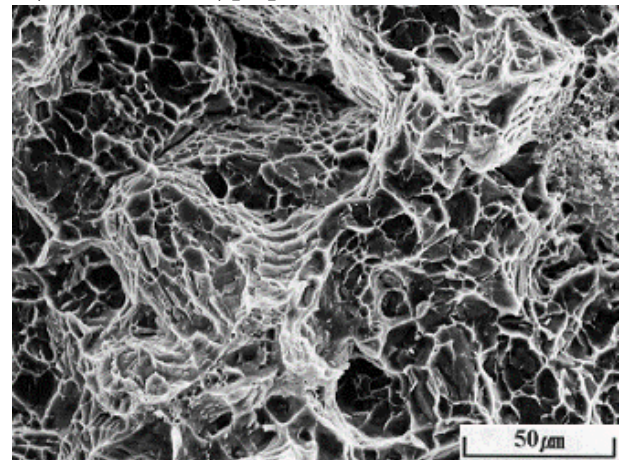

(a) Low magnification

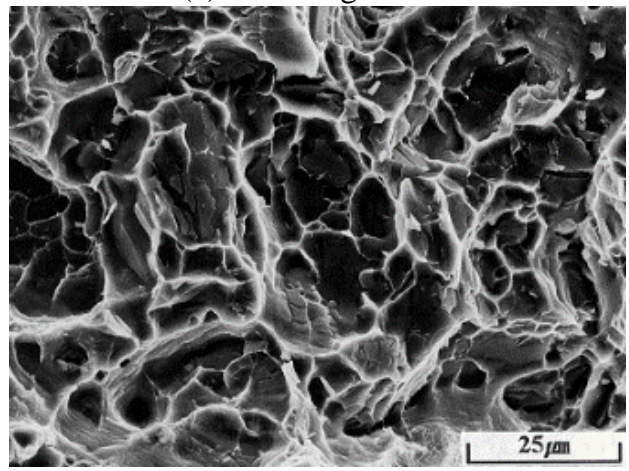

(b) High magnification

Figure 11: SEM fractography of 6061 after DC casting and extrusion (TU)[9]

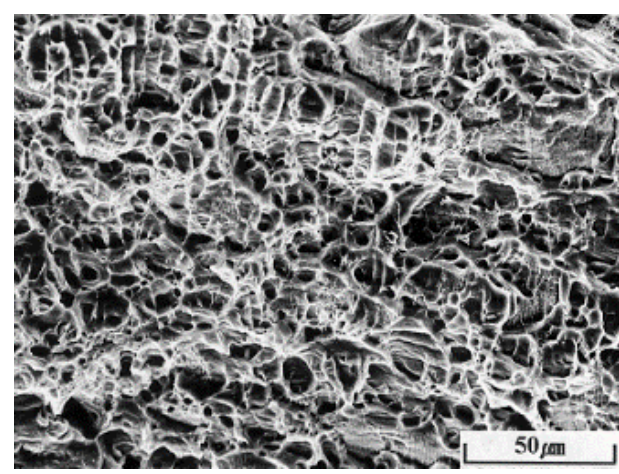

(a) Low magnification

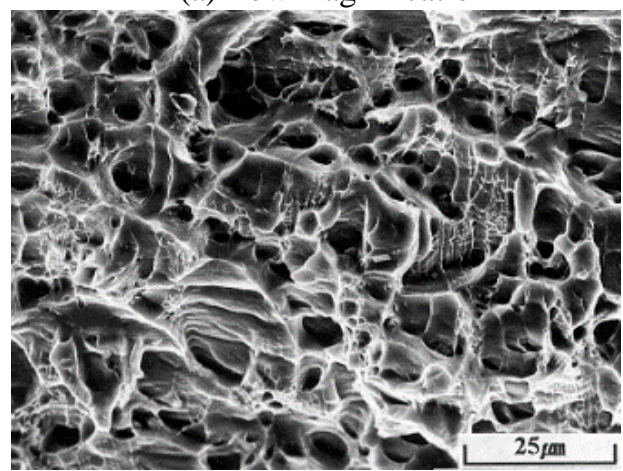

(b) High magnification

Figure 12: SEM fractography of 6N01 after AS casting and extrusion (TU)[9]

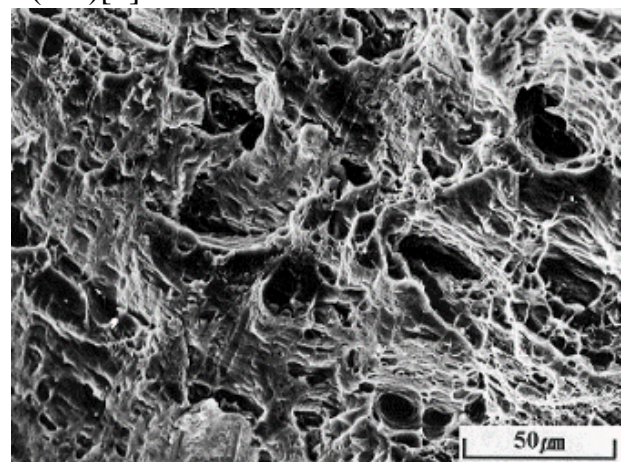

(a) Low magnification

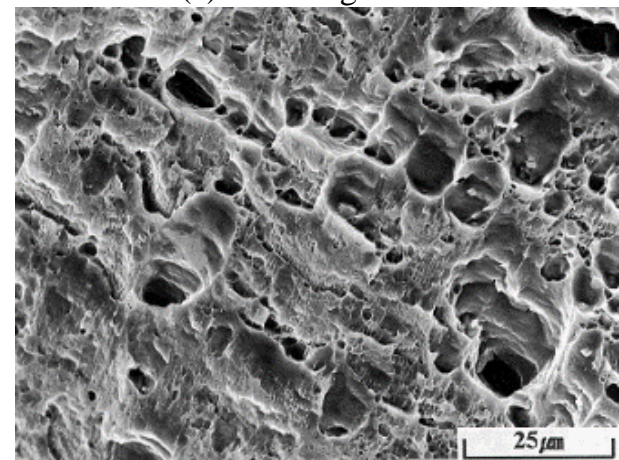

(b) High magnification

Figure 13: SEM fractography of $6063+a$ after AS casting method (Korea H Co.)[9]

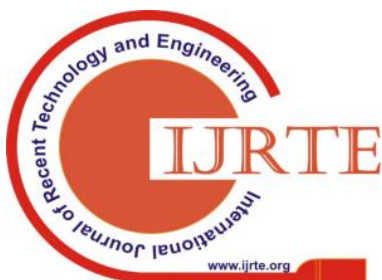




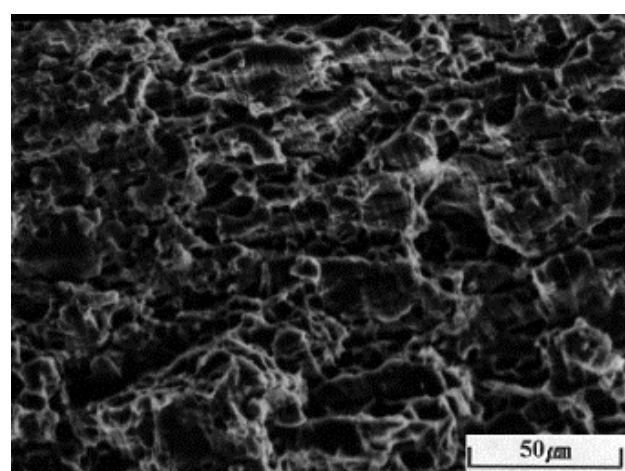

(a) Low magnification

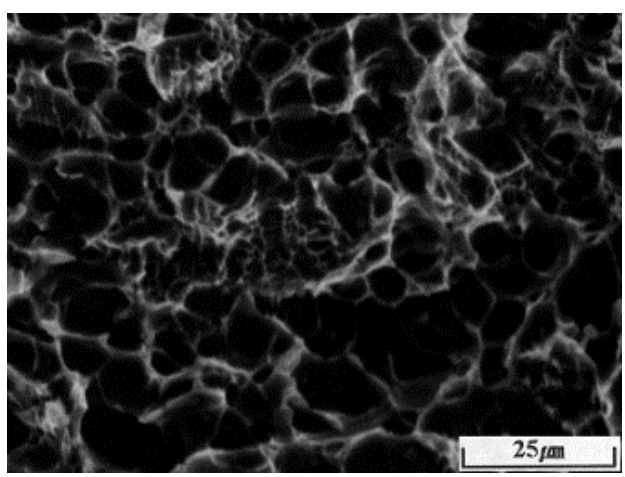

(b) High magnification

Figure 14: SEM fractography of 6061 T5 after AS casting and extrusion (Korea $\mathrm{H} \mathrm{Co}$.)

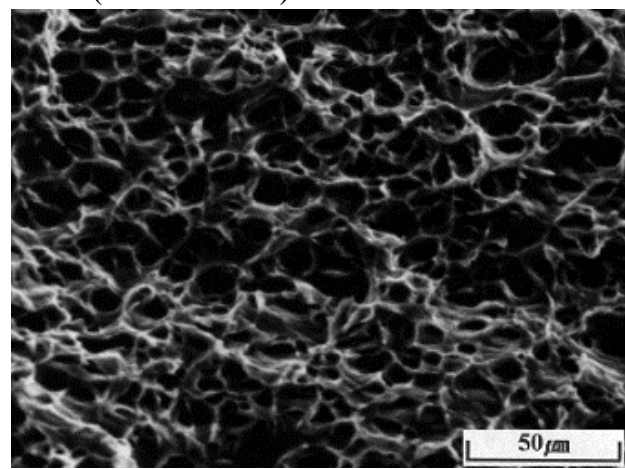

(a) Low magnification

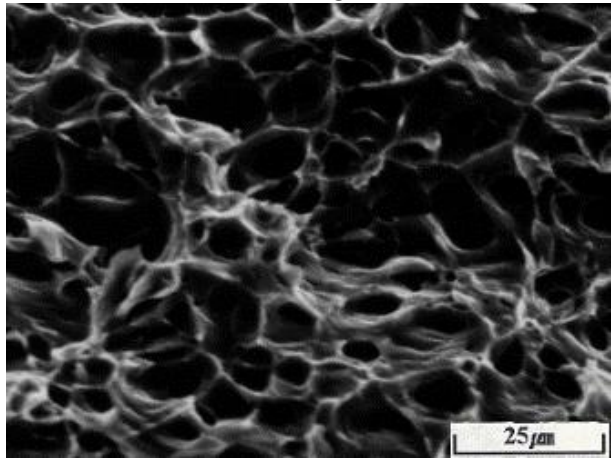

(b) High magnification

Figure 15: SEM Fractograph of 6061 T6 after AS casting and extrusion (Korea H Co.)

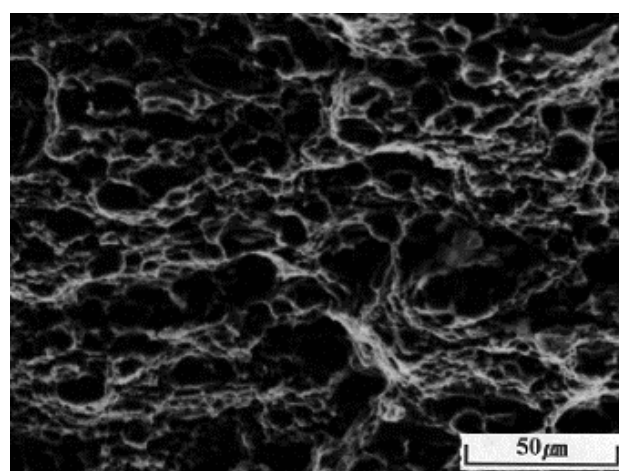

(a) Low magnification

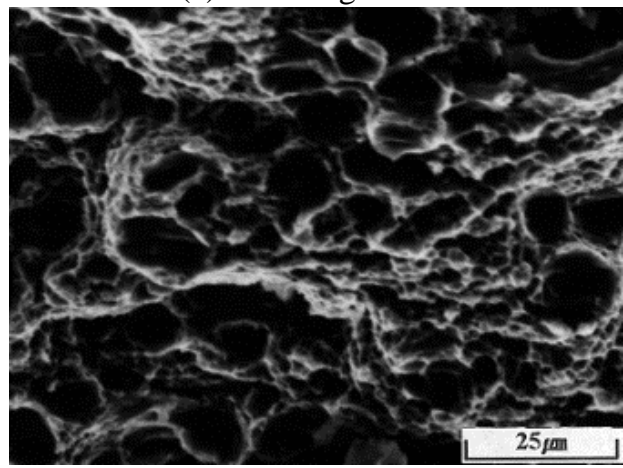

(b) High magnification

Figure 16: SEM fractography of 5083F after AS casting and extrusion (Korea H Co.)

In contrast to these results, the product manufactured by the AS casting method had less impurities and exhibited relatively improved mechanical properties. Therefore, precise impurity management and cooling rate management are required during DC casting method to produce excellent extruded products after casting. Additionally, as Table 1 shows, the extrusion temperature and the extrusion pressure of 6061 alloy were somewhat higher than those of other alloy materials, because the 6061 alloy showed the brittle fracture due to grain boundary segregation (Fig. 11). Additionally, this extrusion test specimen used billet by DC casting method is the main cause as well[9].

\section{CONCLUSION}

It was manufactured by adopting aluminum alloy as the candidate light alloy to be used for interior and exterior materials of high-speed trains. Mechanical properties of the extruded materials were comparable to those of external materials (manufactured by Canada, Alcan). The hardness, microstructure, and extrusion characteristics of AA6063, AA6N01, AA6061, AA6005, AA6060 and AA5083 alloys selected in the present study through literature review are similar to those of external materials (Canada, Alcan). The AS casting billets of AA6005, AA6061, AA6060, AA6063 and 6 N01 alloys of the 6 XXX series and AA5083 of the $5 \mathrm{XXX}$ alloy were selected and extruded. After extrusion, each alloy was heat-treated and its mechanical properties were characterized. It was proved to be sufficient as the interior and exterior materials of high-speed train.

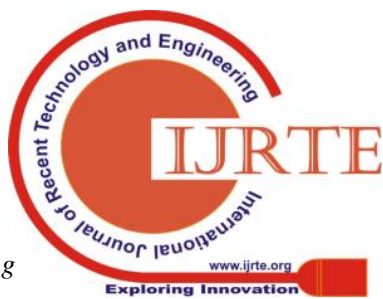




\section{ACKNOWLEDGMENT}

This work was supported by the National Research Foundation of Korea(NRF) grant funded by the Korea government(MSIP : Ministry of Science, ICT \& Future Planning) (No. 2017R1C1B2011285).

\section{REFERENCES}

1. M K. J. Kim \& S. T. Won, "Cast and Characterization of Light-Weight Aluminum Alloys for Interior \& Exterior Parts of High Speed Train" Transaction of KSMT. 20(1). 12-17, 2018.

2. A. K. Vasudevan. \& R. D. Doherty; Academic press, "Aluminum Alloys-Contemporary Research and Applications" Treatise on Materials Science and Technology. 31, 1989.

3. W.-K. Kim. S.-T. Won. B.-C. Goo, "A Study on Mechanical Characteristics of the Friction Stir Welded A6005-T5 Extrusion" Int. J. of Precision Eng. And Manufacturing. 11(6). 931-936, 2010. https://doi.org/10.1007/s12541-010-0113-1

4. K. J. Kim, "Characterization of Cast Alloys for Interior \& Exterior Parts of High Speed Train" Transaction of KSME A. 42(7). 637-642, 2018.

5. Combe, E., Guilmeau, E., Savary, E., Marinel, S., Cloots, R., Funahashi, R., \& Boschini, F, "Microwave sintering of Ge-doped In2O3 thermoelectric ceramics prepared by slip casting process" Journal of the European Ceramic Society, 35(1), 145-151, 2015. https://doi.org/10.1016/j.jeurceramsoc.2014.08.012

6. Ortiz, A. L., Candelario, V. M., Moreno, R., \& Guiberteau, F, "Near-net shape manufacture of $\mathrm{B} 4 \mathrm{C}-\mathrm{Co}$ and $\mathrm{ZrC}-\mathrm{Co}$ composites by slip casting and pressureless sintering" Journal of the European Ceramic Society, 37(15), 4577-4584, 2017. https://doi.org/10.1016/j.jeurceramsoc.2017.07.024

7. Pelegrini, L., Junior, L. E. V., Neto, J. B. R., \& Hotza, D, "Direct coagulation casting of nano-8YSZ powder suspensions using nano-MgO as coagulating agent" Ceramics International, 43(1), 316-323, 2017. https://doi.org/10.1016/j.ceramint.2016.09.158

8. Mortensen, D., Henriksen, B. R., M'Hamdi, M., \& Fjær, H. G, ”Coupled modelling of air-gap formation and surface exudation during extrusion ingot DC-casting. In Essential Readings in Light Metals" (pp. 812-818). Springer, Cham, 2016.

9. K. J. Kim \& S. T. Won, "Characterization of Aluminum 6xxx Series Extruded Alloys for Interior \& Exterior Parts of High Speed Train" Transaction of KSMT. As submitted, 2018.

10. Xin, R., Wang, M., Liu, Z., Chen, X., Huang, G., \& Liu, Q, "Evaluation of Textural Effect on the Rollability of AZ31 Alloys by Wedge- Shaped Sample Design" Advanced Engineering Materials, 19(7), 1700035, 2017. https://doi.org/10.1002/adem.2017000

\section{AUTHORS PROFILE}

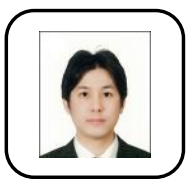

Tae-Kook Kim received his B.S., M.S., and Ph.D. degrees in Electrical Engineering from Korea University, Seoul, Korea in 2004, 2006, and 2014, respectively. From august 2006 to February 2010, he was with the Mobile Communication Technology Research Center at LG Electronics Co. Ltd. of Korea. From September 2014 to February 2016, he was with Mobile Communications Business at Samsung Electronics Co. Ltd. of Korea. Since March 2016, he has been a professor at Department of Information and Communications Engineering, Tongmyong University. His current research interests include wireless LAN, indoor localization system, mobile content delivery network (CDN), distributed network, personal area network, Internet of things (IoT), Public Safety LTE (PS-LTE), and Virtual Reality (VR)/Augmented Reality (AR).

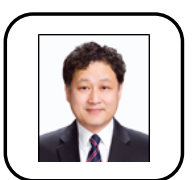

Kee Joo Kim is a professor of Tongmyung University. He specialized in mechanical engineering in school years. He got ph. D award from school of material science and engineering in Seoul National University. He has experience to work in Ssangyong Motor Co. for about 16 years. In there he had been worked about design of automobile components by using computer aided engineering based on finite element method. 